\title{
Integrating Multiple Ecosystem Services Into Ecological Site Descriptions
}

\section{By Wendell Gilgert and Steve Zack}

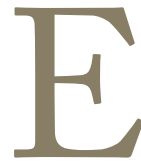

cological Site Descriptions (ESDs) represent an emerging tool to assist land managers and owners in understanding their landscapes and how they work, or function, in an ecological context. Ecosystem services are those resources and processes supplied by natural ecosystems and sites that can be viewed as benefits to society and, conceptually, natural capital assets with the capacity to be assigned economic values. ${ }^{1}$

The definitions of ecosystem services were formalized by the United Nations 2004 Millennium Ecosystem Assessment (MA), ${ }^{2}$ which is a report resulting from a four-year study involving more than 1,300 scientists worldwide. This report grouped ecosystem services into four broad categories: provisioning, such as the production of food and water; regulating, such as the control of climate and disease; supporting, such as nutrient cycles and crop pollination; and cultural, such as spiritual and recreational benefits.

Despite the recognition provided in the MA report, there are numerous examples in which the values of ecosystem services go unrecognized, leading to great economic, cultural, biologic, and aesthetic loss. A notable example of a lack of recognition of ecosystem services can be seen in American wetland ecosystems. From the time North America was settled by Europeans until the passage of the Clean Water Act (CWA) of 1972 (which made the destruction and conversion of many wetland types illegal), wetlands were drained, filled, and otherwise converted, for use of agricultural production, mining, timber harvest, dam construction, and urban development on immense scales. Events leading to the passage of the CWA resulted in the recognition that those "swampy, mosquito infested, mucky bogs" actually did have value for something besides frogs and the occasional duck. Aided by the proclamation of "No Net Loss" of wetlands by President George Bush in 1989, the American public became aware of the long list of values and ecosystem services provided by wetlands, including groundwater discharge, flood attenuation, sediment stabilization, sediment/ toxicant retention, nutrient removal/transformation, aquatic and wildlife diversity/abundance and habitat, and a wide array of recreation opportunities.

Here, we highlight, in examples from the American West, the strong role key wildlife species play in effecting transitions of ecological character and function on specific ecological sites and the services provided by those ecosystems. It is in this intersection where landscape, the potential for transition to or from desired states, the subsequent ecosystem services proffered or reduced, and the often-controversial role of certain wildlife species collide. Understanding how ecological sites can transition from one state to another is poorly understood in many cases. Our interest is in integrating wildlife conceptually and practically into the identification of ESDs; determining how some wildlife can effect transitions is another interest. Wildlife can influence our understanding of sites and their dynamics. Finally, we frame both the potential utility of the ecosystem services concept and its limitations, using examples from key ecological sites. The ecosystem service literature is large and growing, concerning itself with water cycles, energy flow, clean air and water, nutrient cycling, and other ecosystem processes. Here, we will consider ecosystem services more narrowly in the context of transitions among states and wildlife activities, briefly described below.

The dynamics of soil-vegetation interactions on ecological sites are described in state-and-transition models (STMs) (Fig. 1). These STMs evaluate how sites in a particular condition, or "state," can change, or "transition," to very different states, in both biological and physical dimensions. Different states or community phases on the same site, in principle, could provide a very different combination of ecosystem services.

Across much of the western United States, the majority of existing ecosystems no longer represent historical conditions. This broadly is true because of altered ecosystem processes (changes in "drivers" such as climate and land use) 


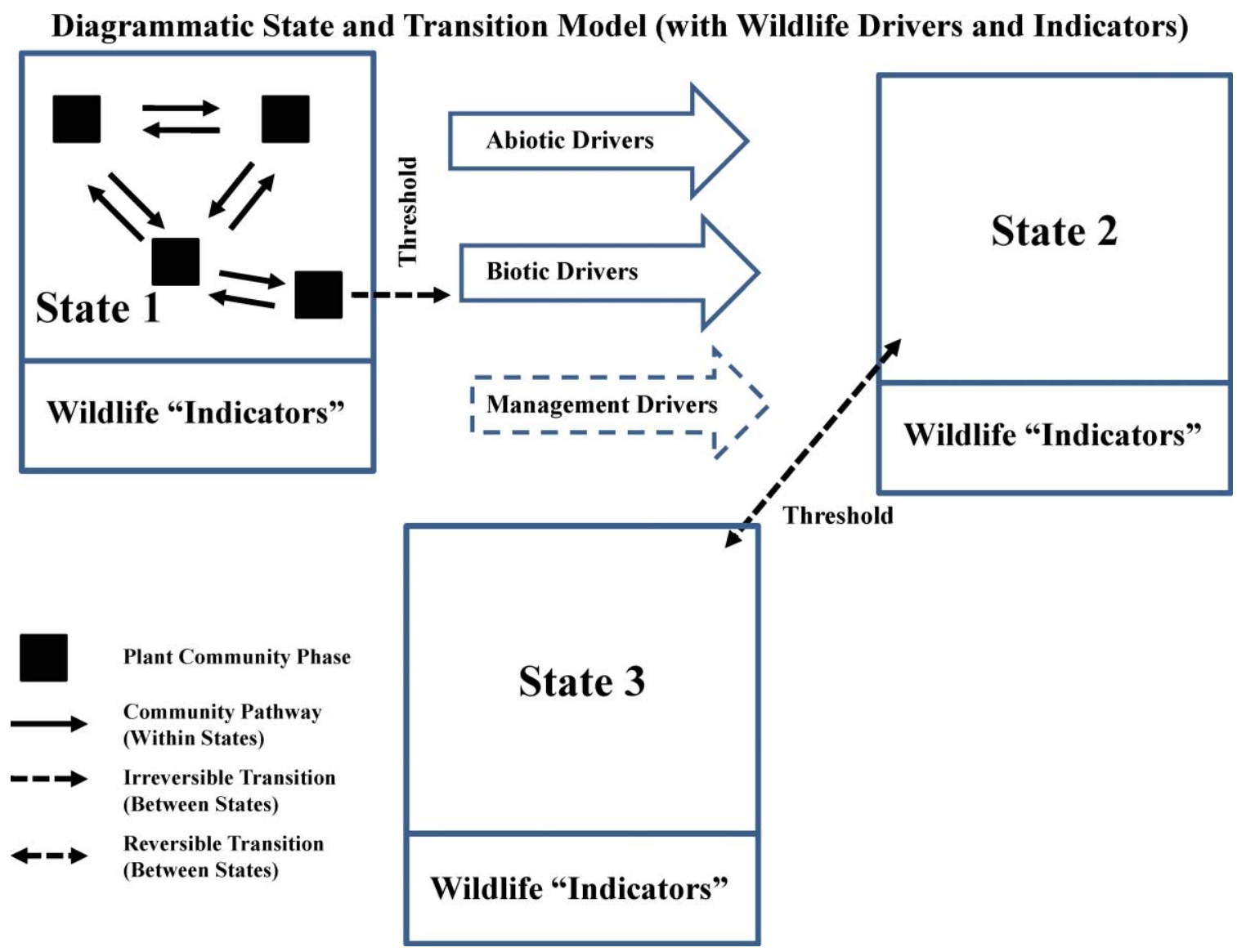

Figure 1. A diagrammatic representation of a state-and-transition model, including the integration of how wildlife species might act as indicators of different states, and how key wildlife can "drive" transitions through their ecological actions. Three hypothetical states from one hypothetical site are shown. State 1 shows how plant community phases, often successional phases, can occur within a state. Thus, a state at a site can vary as to the detail of its vegetation, but not necessarily function differently. Wildlife species representative of a given site can act as "indicators" informing managers of key vegetations, of approaching thresholds, and of other attributes of a site by their occurrence. A given state can change (e.g., from State 1 to very different State 2, or from State 2 to 3 ) if critical "drivers" (both abiotic and biotic) act to change the condition dramatically with actions resulting in a separate state very different in vegetation and function. Different management actions, either intentional or unintentional, also can drive transitions. Such transitions can be irreversible (as indicated in the transition from State 1 to State 2), or reversible (as indicated between States 2 and 3). A comprehensive Ecological Site Description would lay out the potential different states of a given site, and indicate the specific abiotic and biotic drivers that affect the transition between states. See the text for examples of states and transitions, and the wildlife indicating and affecting them.

and the impact of invasive species (plant, animal, and other) that alter composition and function, and eliminate or replace indicator wildlife species in sites. ESDs offer a valuable tool to land managers for evaluating the potential of particular soil/climate combinations to produce a range of ecosystem services, some of which might not have existed in their historical state.

Implicit in the definition of ecological sites is that they are soil-based. Because soils are the product of geologic parent material, climate, living organisms, topography, and time, the resultant physical characteristics of hydrology, including runoff and infiltration, and the plant community create distinct ecological sites.

Ecological sites are exciting and newly recognized means to integrate the best attributes of the former system of range sites and woodland suitability indices into emerging scientific understanding, and include STMs as a means to describe vegetation dynamics. Ecological sites are an indispensible conservation design and implementation tool. Well-developed ecosites offer the conservation practitioner a blueprint for vegetation (habitat) management and restoration that replaces guesswork or partially informed restoration or management prescriptions, with a high level of scientifically peer-reviewed certainty. The practical value, use, and application of an ESD can be distilled into three broad categories:

1) Decision Support for Management and Restoration: Data collected for plant community phase(s) within the STM are arranged by cataloging each plant species identified on the site into plant functional groups. These functional groups serve as a blueprint for essential vegetation elements and a pathway to facilitate biotic and abiotic processes (e.g., fire and herbivory) that are essential for restoration and management. Identifying wildlife 
species that can act as indicators of ecosites, through their specific relationships to the habitat and the ecological processes, can aid in the identification by managers of the ecosite in question.

2) Risk Assessment: The use of STMs in conjunction with interpretive information allows the user to appraise the risk associated with a management or restoration action. For example, a user can assess the probability of success or failure when deciding to restore a site dominated by invasive species back to a reference plant community. Are the labor, time, and cost worth the restoration action? Are the relevant wildlife species present or do they present insustainable densities (e.g., apex predator or ungulate densities)?

3) Performance Criteria: An ESD provides the user with vegetation dynamics found in the STMs and with the vegetation functional groups that are essential for functional restoration. They are criteria that can compare actual management and/or restoration results with those expected from the site. Both wildlife indicators and the presence/ absence of wildlife drivers can also aid management here.

An ESD can be viewed as a recipe with ingredients (community phase vegetative functional groups) and instructions (STMs and community dynamics descriptions). Conceptually, the potential integration of ecosystem services could bridge the restoration and management of a site through its natural capital to its societal and economical values, providing flavor and nuance that has up to now been missing.

\section{Real World Examples of Using Ecological Sites to Identify Ecosystem Services From the American West}

To integrate the concept of ecological sites with wildlife as both indicators of approaching or crossing vegetative community thresholds and drivers of transitions, we draw upon our collective experience in sites and habitats across the American West. The following examples also offer

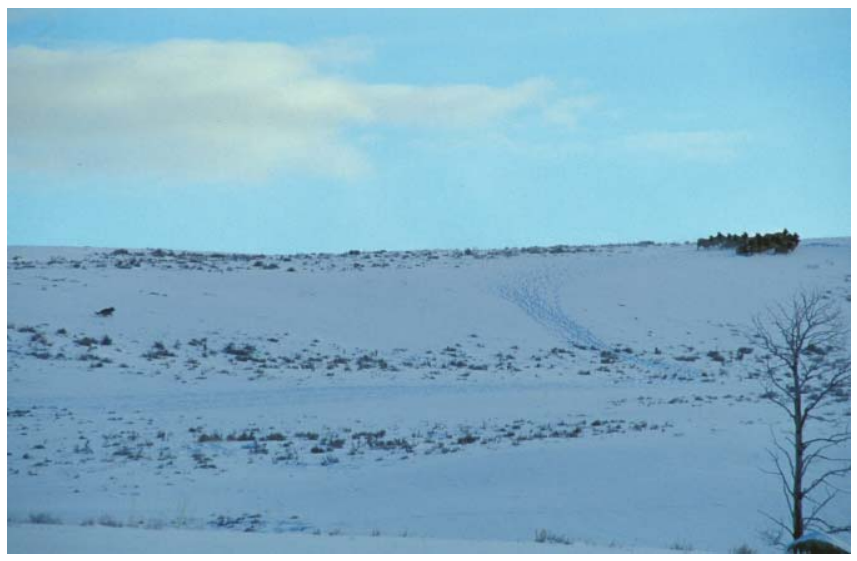

The reintroduction of wolves to Yellowstone has moderated the impacts of elk on aspen communities. (Photo courtesy Steve Zack) an opportunity to reflect on potential ecosystem services arising from these sites and the critical context of wildlife species as drivers of ecological interactions and processes that affect ecological states and thus frame the value of those potential ecological services that might be gained from these landscapes.

1) Elk and Aspen: Aspen (Populus tremuloides) is an enormously important tree species for wildlife amid mixed conifer forests and higher elevation settings throughout the West. Indicator wildlife of aspen groves include sapsuckers (Sphyrapicus spp.) and ruffed grouse (Bonasa umbellus). Fire suppression has disrupted the natural cycle of aspen regeneration, and, increasingly, dense populations of elk and other herbivores (including livestock) have suppressed aspen age class recruitment. Abiotic (fire) and biotic (excessive harvest as a result of high densities of elk and cattle) drivers have played a large role in the transition of aspen and conifer landscapes to those depauperate of aspen. The successful reintroduction of wolves (Canis lupus) into the Yellowstone ecosystem has revealed a strong role for these carnivores in moderating the effects of ungulates on this ecosystem. ${ }^{3}$ By moving potential prey via the risk of predation, wolves are in effect acting as drivers in maintaining the state or reversing this transition (Fig. 2). Paradoxically, wolves could be playing an ecosystem service role in reversing degradation of woody species browsed by ungulates.

2) Beavers and Riparian Sites: Beavers (Castor canadensis) are rightly recognized as ecosystem engineers. Through a dynamic pattern of dam building, active movements (and abandonment of areas), and felling of large and small trees, beavers create a mosaic of habitats within a riparian system resulting in a watershed acting more like a sponge than a drainage system. Absent beavers (whose populations have been widely reduced from historic population levels and locally extirpated), riparian systems in the West are largely degraded in association with improper

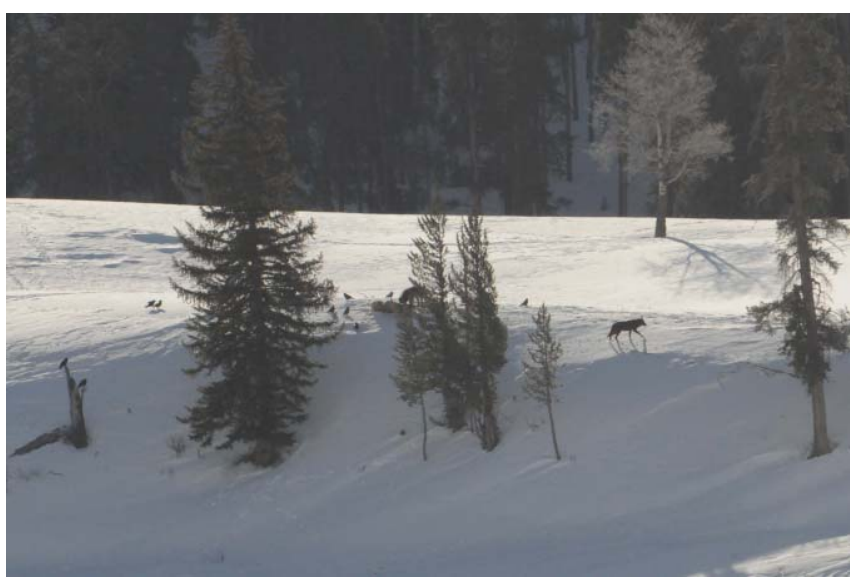

Predators such as wolves (seen here near an elk carcass) should be included as drivers in state-and-transition models. (Photo courtesy Steve Zack) 


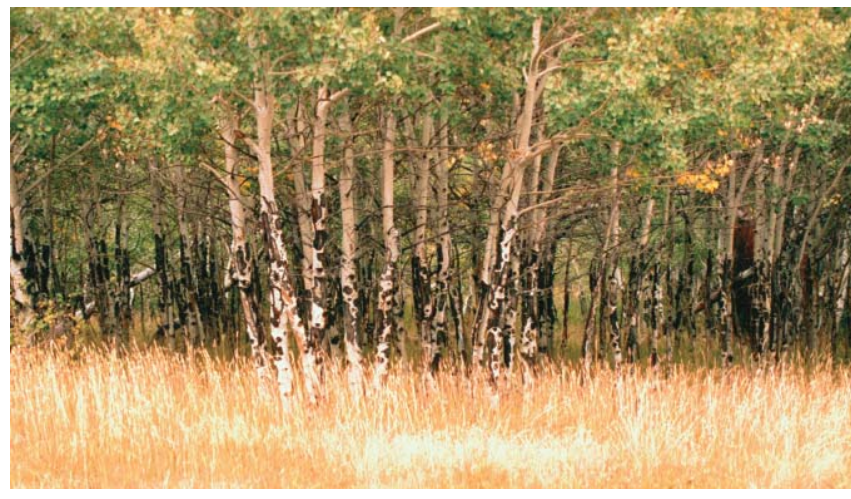

Heavy use by elk suppresses aspen regeneration. (Photo courtesy Wendell Gilgert)

cattle management and wild ungulate herbivory. The reintroduction of beavers widely into Wyoming, for example, has led to riparian areas with recharged water tables, enhanced water storage capacity, and new habitats for riparian wildlife such as migratory songbirds. ${ }^{4}$ Clearly, the cost to society of recharging these essential water systems has been very high since the time of extensive trapping of beavers. Beavers provide numerous ecosystem

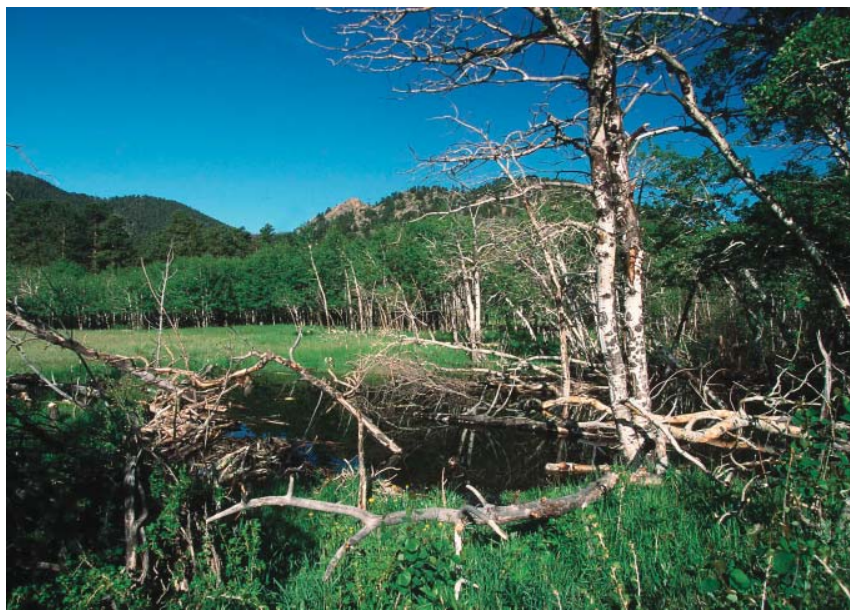

By damming streams, beavers impact the hydrology and plant communities of an ecological site. (Photo courtesy Gary Kramer)

services, although human inhabitants within the watersheds and wetlands might desire an alternative set of services!

3) Oak Regeneration and Acorn Dispersal: In California's Central Valley and associated foothills, oak tree diversity

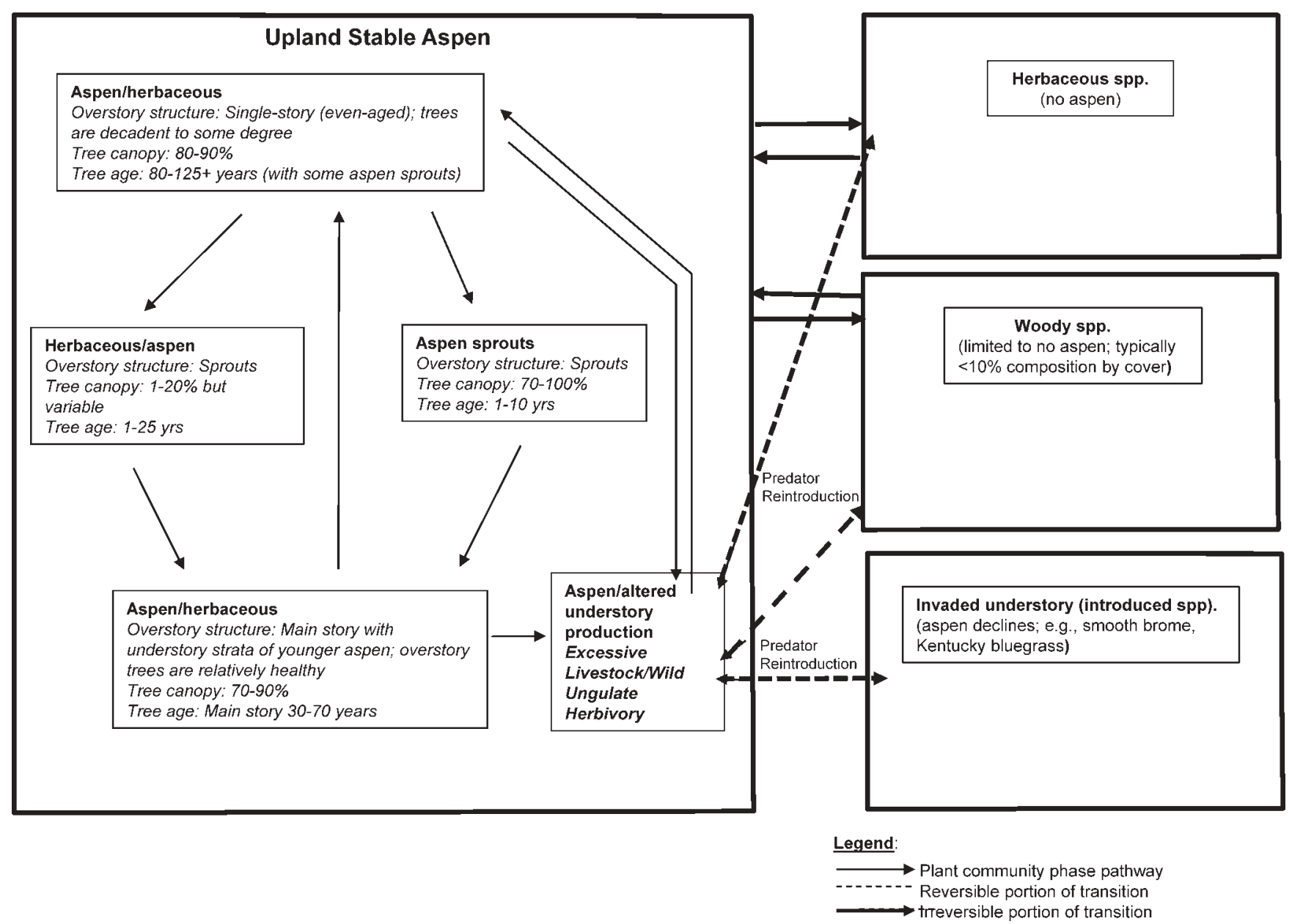

Figure 2. State-and-transition model showing impacts of predator drivers on the relationship between elk and aspen. 
is its highest in the United States. Oaks (Quercus spp.) and their seeds (acorns) are critical to the wildlife food chain. They are a California cultural icon and highly valued by society, even dating back to native Californians. Yet, oaks are in trouble. Regeneration of many species is virtually nonexistent, particularly for blue oaks and valley oaks. Sudden oak death is crippling many other species. Management action in oak woodlands to remove scrub understory (to increase grass productivity for livestock forage) has affected the most important disperser of acorns, the Western scrub jay (Aphelocoma californica). These jays bury as many as 5,000 acorns a year, and their incomplete retrieval is the means by which oaks typically sprout from acorns. Within ecological sites representing oak woodlands, there is a risk of transitioning to weedy grasslands absent jay scrub habitat. Western scrub jays are important drivers needed to avert this disaster, but only can be present if we recognize and reverse the management drivers that keep scrub out of the woodlands.

4) Forests, Fire, and Woodpeckers: In ponderosa pine forests east of the Cascade/Sierra axis of mountains, lowintensity fires historically acted (i.e., acted as abiotic drivers) to open park-like forests dominated by large pines. Wildlife such as white-breasted nuthatches (Sitta carolinensis) and olive-sided flycatchers (Contopus cooperi) are indicative of such open forest settings. With fire suppression and the changing climate generating more drought-like conditions, these forests have changed dramatically in forest structure and composition (an unintended management-driven transition). Many areas now are dominated by dense forests of mixed conifer species and are at greater risk of intensive and standreplacing fires. Woodpeckers, particularly black-backed woodpeckers (Picoides arcticus) and hairy woodpeckers (P. villosus), excavate cavities in dead trees for nesting, and disused cavities are taken over by numerous species of birds and mammals for their nesting and roosting.

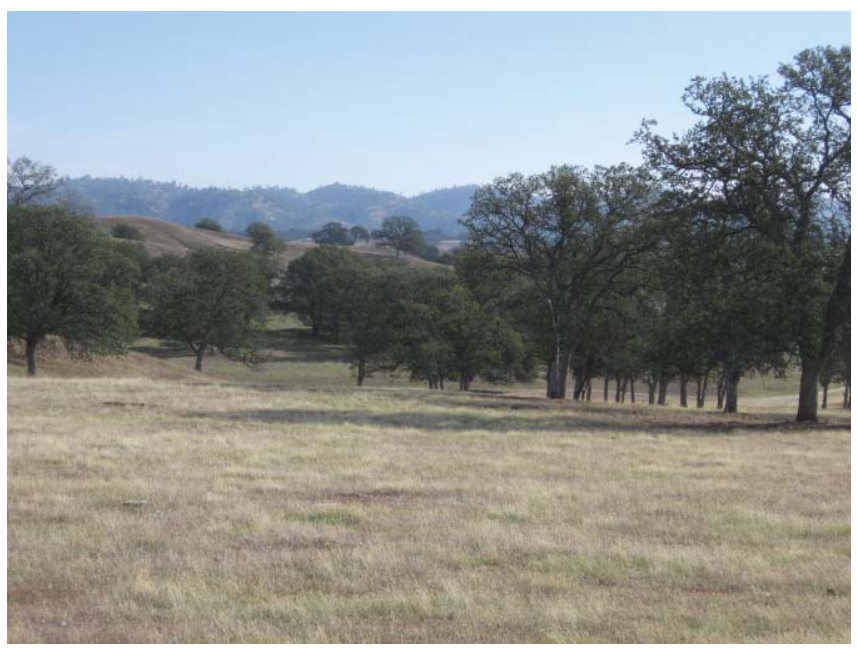

A grove of Blue Oak without regeneration. (Photo courtesy Wendell Gilgert)

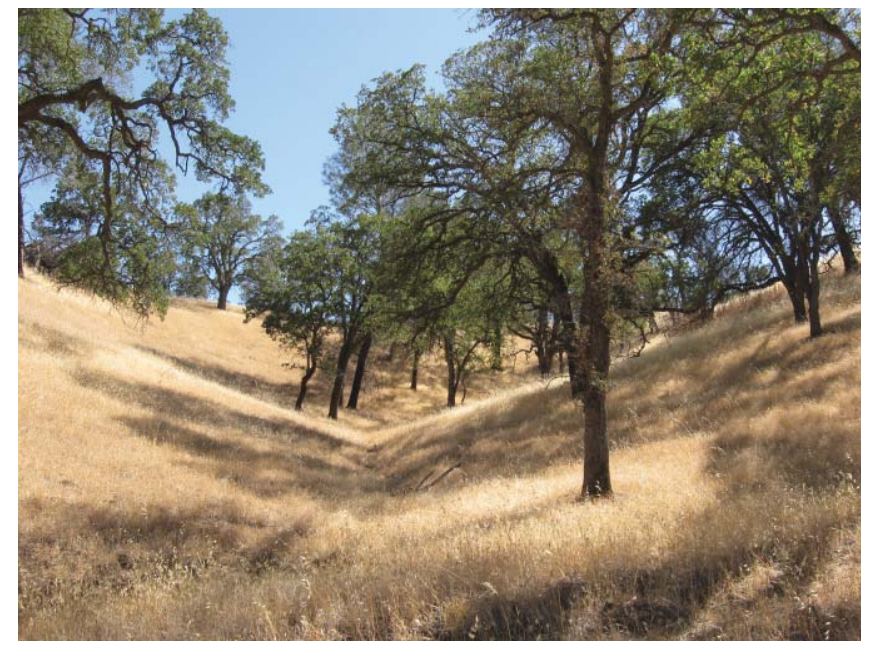

The removal of shrubs has reduced the presence of acorn-burying scrub jays and resulted in a lack of Blue Oak regeneration. (Photo courtesy Wendell Gilgert)

Forest management efforts to thin and return low intensity fires to these forests have made clear the capacity to transition back to open stands dominated by ponderosa pine. These efforts have also revealed how woodpeckers interact with decay fungi while foraging on bark beetles, which in turn have responded with fires by infesting weakened trees. It seems that the capacity for woodpeckers to later excavate cavities is influenced by such interactions between foraging woodpeckers, decay fungi, and bark beetles. ${ }^{5}$ Although woodpeckers provide an ecosystem service in enhancing diversity by creating nesting cavities, the process also includes fire, decay fungi, and bark beetles. Fire and bark beetles otherwise would not be thought of as services to forests, and so this acts as another reminder that the context of the ecological setting is paramount in understanding the potential and actual services rendered.

5) Bison, Prairie Dogs, and Prairie Grasslands: The Great Plains of North America were once dominated by bison (Bison bison) and black-tailed prairie dogs (Cynomys ludovicianus); the former grazed, defecated and urinated, pounded, and wallowed; the latter cleared out colonies of most vegetation and aerated soils with their burrows. The effect was a very heterogeneous landscape of structure and composition of grasses. That heterogeneity historically provided habitats for (indicator) species such as mountain plover (Charadrius montanus), lesser prairie chicken (Tympanuchus pallidicinctus), and numerous grassland sparrows. Western expansion, with tillage and domestic livestock grazing, has transformed much of the Great Plains. For those grasslands that remain, their structure and grass diversity has been greatly diminished. As a result, grassland birds as a group are in the greatest decline of all habitat-groupings of birds, and many other wildlife species are in peril. There are many new efforts underway to bring back bison as ecological species in 


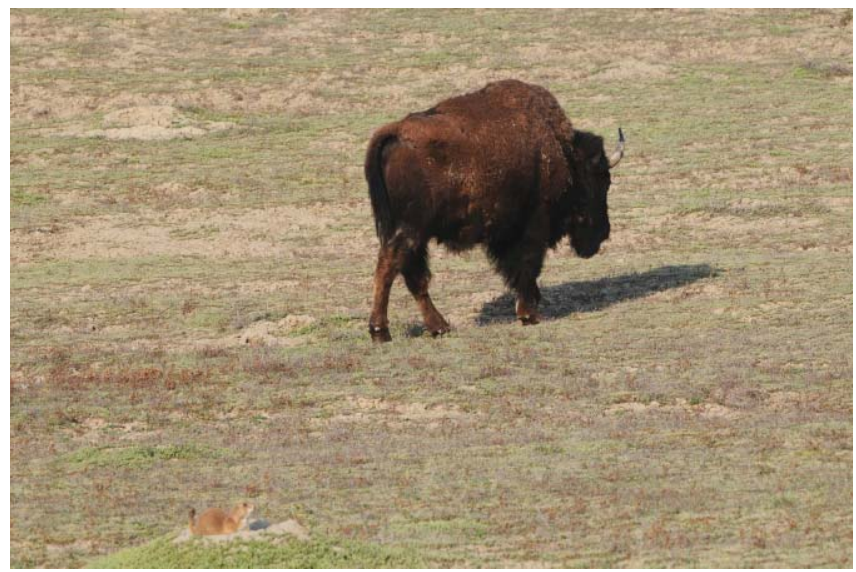

Both the prairie dog and bison can impact the state of an ecological site. (Photo courtesy Steve Zack)

several parts of the Great Plains. Yet, how do we induce movements of bison across landscapes in the absence of predators? Can prairie dogs be part of this equation, or does their "pest" status impede opportunities to recolonize them widely? Both species can help drive the transition of Great Plains grasslands back to ecosites with diverse structure and composition, and thus provide conditions conducive to reviving grassland wildlife.

Our outline of different western sites and their drivers in large part is intentionally provocative. Prairie dogs, beavers, and bark beetles clearly are considered pests in most other contexts. Likewise, wolves and fire usually are not associated with ecosystem service to the general public. Nonetheless, their inclusion as indicators or drivers in the above examples indicates that the distinction between ecosystem service and ecosystem "disservice" is one of context and perception. It also seems clear to us, in the examples we outlined, that drivers of state transitions that come from management ("Management Drivers" in Fig. 1) often unintentionally act to change community phases or states. Fire suppression is a prevalent example in the West; widespread improper cattle grazing and its manifold deleterious ecosystem effects is another. Further, those management drivers meant to act as surrogates to intentionally affect state transition are often imperfect in re-establishing desired states. Widespread application of forest thinning and deployment of prescribed fires come to mind. Brush management, meant to improve and increase forage, also has a legacy of unintended effects on ecosystems.

Although ESDs provide context along with some evidence to describe ecological processes, most notably vegetation dynamics and, to a lesser extent, the hydrologic cycle function, data and interpretations for most other natural processes such as energy flow, nutrient cycles, and pollination are absent. Ecosystem processes interact with and affect each other. Similarly, up until now, ecosystem services are not represented because a process is not equal to a service.

Nature is indifferent. Humans viewing nature through our anthropogenic lens place value-positive, negative, or indifferent-on ecological services. An ecological service can be beneficial when delivered to natural systems, yet in the human context, the capacity of an essential service in one situation can be viewed as a disservice in another. For example, although we know beavers provide water retention and storage and essential habitat to a wide variety of fish and wildlife through actions that create beneficial habitats, if the flooding caused by their dams creates problems for managers of those lands, they are viewed as detrimental and will be removed. Thus the importance of understanding the system as a whole, and its ecological processes, is essential before we can properly view an ecosystem service as a benefit.

If ecosystem services are indeed to take on a commoditylike role in landscape management and restoration, then we must be careful when we identify our target ecological sites and understand the drivers, including wildlife drivers, that can move us in those directions. For land owners and managers, the provision of ecosystem services, consistent with their land's bottom-line interests, can be greatly informed by ESDs and STMs.

\section{References}

1. Maczko, K., And L. Hidinger, eds. 2008. Sustainable rangelands: ecosystem goods and services. SRR Monograph No. 3. Sustainable Rangelands Roundtable. Fort Collins, CO, USA: Colorado State University, Warner College of Natural Resources. $111 \mathrm{p}$.

2. Millennium Ecosystem Assessment (MEA). 2005. Ecosystems and human well-being: synthesis. Washington, DC, USA: Island Press. 155 p.

3. Beschta, R. L., and W. J. Ripple. 2010. Large predators and trophic cascades in terrestrial ecosystems of the western United States. Biological Conservation 143(10):2249-2412.

4. Соoк, H. A., AND S. W. Z Ack. 2008. Influence of beaver dam density on riparian areas and riparian birds in shrubsteppe of Wyoming. Western North American Naturalist 68(3):365-373.

5. Ferris, K. L., M. J. Huss, and S. W. ZAck. 2004. The role of foraging woodpeckers in the decomposition of ponderosa pine snags. Condor 106:50-59.

Authors are West Region Wildlife Biologist, USDA-Natural Resources Conservation Service, West National Technology Support Center, Portland, OR 97232,USA, Wendell.Gilgert@ por.usda.gov (Gilgert); and Conservation Scientist, Wildlife Conservation Society, Portland, OR 97205, USA (Zack). 